\title{
The Supply Side of the Digital Divide: Is There Equal Availability in the Broadband Internet Access Market?
}


JEL categories: L96, J78, L51

\title{
The Supply Side of the Digital Divide: Is There Equal Availability in the Broadband Internet Access Market?
}

\begin{abstract}
The newest dimension of the Digital Divide is access to broadband (high-speed) Internet service. Using comprehensive U.S. data covering all forms of access technology (chiefly DSL and cable modem), I look for evidence of unequal broadband availability in areas with high concentrations of poor, minority, or rural households. There is little evidence of unequal availability based on income or on black or Hispanic concentration. There is mixed evidence concerning availability based on Native American or Asian concentration. Other findings: rural location decreases availability; market size, education, Spanish language use, commuting distance, and Bell presence increase availability.
\end{abstract}

James Prieger

Assistant Professor

Department of Economics

University of California

One Shields Avenue

Davis, CA 95616

Phone (530) 752-8727

Fax (530) 752-9382

E-mail jeprieger@ucdavis.edu. 


\section{INTRODUCTION}

The Internet has transformed the way Americans work, play, and shop. A new wave of Internet accessibility, the availability of broadband (high-speed) access, has the potential to be as revolutionary as the first wave. Broadband access, usually through Digital Subscriber Line (DSL) or cable modem technology for residences and leased lines for businesses, allows users to send and receive enormous quantities of data, audio, video, and voice communication, and relaxes the constraints of the "World Wide Wait". With every technological revolution comes the possibility that some will be left behind. The so-called "Digital Divide"- - the well-documented gap in computer and Internet usage between richer and poorer households, whites and certain minority groups, and urban and rural areas ${ }^{1}$ - has received much attention in the past few years, both in policy circles and the popular press.

The public-policy focus on the Digital Divide is shifting toward broadband Internet access. In a widely cited report, the Department of Commerce (NTIA, 2000) finds that in terms of household broadband subscription, black and Hispanic households lag white households, rural areas lag urban areas, and poorer households lag more affluent households. Such findings commingle non-adoption of broadband access by households and non-implementation of the technology by carriers. One unanswered question, therefore, is whether groups lacking broadband access are deprived because broadband services are not available where they live. Preliminary findings by the Federal Communications Commission (FCC, 2000a) indicate that broadband is less likely to be available in rural and lower-income areas. While lacking direct evidence, the FCC (2000a at 241) furthermore concludes that "minority customers are vulnerable to not having access to advanced services in as timely a fashion as most other Americans." Faulhaber and Hogendorn (2000) conclude from a model based on engineering data that the unconstrained market at maturity will leave at least twelve percent of U.S. households without broadband avail- 
ability, due to cost and demand considerations. Findings such as these lead some observers and interest groups to charge that market forces are leading to the unequal availability of broadband, ${ }^{2}$ with some advocates going as far as charging broadband carriers with "redlining", 3

These charges warrant careful study for three reasons. First, federal policies currently proposed to narrow the broadband Digital Divide are based on an incomplete examination of the data. Such policies include a host of pending legislation in the $107^{\text {th }}$ Congress. ${ }^{4}$ The FCC is also actively involved in monitoring the Digital Divide, because it is charged by the Telecommunications Act of $1996^{5}$ to monitor and encourage the "reasonable and timely" deployment of broadband to "all Americans". Although it has not done so yet, the FCC has the authority to add broadband to the list of services supported under federal Universal Service programs if it deems necessary. Second, since availability is a precondition for access, any analysis of the Digital Divide must begin with the supply side. Third, broadband is an important technology whose study advances the empirical literature on the economics of diffusion.

This study explores the causes of the unequal availability of broadband. Do the racial composition, income, and rural location of an area affect whether broadband is available? The results contain some surprises. Simple regressions imply that high concentrations of poor, minority, and rural households decrease the probability of broadband access. However, after controlling for cost conditions, other demand factors, and competition in local telephony the income and minority effects largely disappear. Among racial composition factors, only those for Native Americans and Asians have significant negative effects on broadband availability. Those for blacks, ethnic Hispanics, and other nonwhite races have no significant impact. Even for Native Americans and Asians, the negative effects on access disappear in some areas when language of the household is taken into account. Furthermore, a nonparametric investigation shows the evidence for the dis- 
advantage of Native Americans and Asians is inconsistent across the range of the race variables. More important determinants of broadband availability are demand characteristics such as age, education, commuting time to work, gender ratio, and size of businesses in the area.

A few studies have looked at demand for broadband services by individuals (Madden et al. 2000; NTIA 2000). Fewer studies have looked at the supply side of the market, in large part due to the difficulty of gathering data on DSL and cable modem rollouts. A new, nearly comprehensive broadband survey by the FCC enables study of the supply of broadband for the first time using data from the entire United States. My approach is closest to that of Gabel and Kwan (2001), who study broadband availability at 287 wire

centers. ${ }^{6}$ The present study, on the other hand, covers services offered through nearly all of the more than 22,000 wire centers. Gillett and Lehr (1999) study cable modem access in the 3,133 U.S. counties. Counties are relatively large for the purpose of determining broadband coverage, given, for example, that DSL is typically available only within 3.5 miles of a central office. The present study takes the ZIP code to be the unit of observation, yielding a potential 29,769 observations. The next section discusses implications of using ZIP code areas.

The next section outlines the empirical strategy I use to investigate the causes of the unequal availability of broadband. Section III overviews broadband technology, section IV describes the data, section $\mathrm{V}$ presents the results, and a final section discusses policy implications.

\section{EMPIRICAL STRATEGY}

As in Berry's (1992) model of airline entry, I model the decision by a broadband carrier to enter a geographic market as depending on the expected demand in the area, costs, and entry by other firms. Unlike Berry (1992), I employ reduced form models. 
The main estimations are probit models on a binary variable for broadband availability of any type in a ZIP code area, and model entry as a flexible function of regional demographic, economic, and competitive information. The empirical strategy is to examine the coefficients on the variables reflecting minority composition, rural location, and lowincome areas, because of the policy concern mentioned above that these areas are vulnerable to lagging in broadband access. Previous governmental studies have emphasized the race, income, and rural dimensions of the Digital Divide (FCC 2000b; NTIA 2000), but those studies examine each variable in isolation through simple cross-tabulations without controls. Interpreting results from such studies requires care, as the following illustration shows.

Jump ahead for the moment to the first results reported in Section V, from a simple estimation including variables for minorities, urban/rural location, and fixed effects for Bell companies and states only (Table 2, first columns). The negative and significant coefficient on \% black indicates that the higher the percentage of blacks in an area, the lower is the probability of broadband access. Studies of redlining in the mortgage lending market such as Tootell (1996) point out that there are three possible reasons for such a finding. First, the relationship could be causal, due to entrants' expectations that black households have lower demand for broadband service. In this case, carriers do not enter because they expect profit to be too low to support entry. Second, the relationship could be causal, but in this case based not solely on expected profit but on Becker's (1971) "taste for discrimination". In this case, carriers do not enter some areas even though they would support entry, merely because of racial discrimination. This second case comes closest to "redlining" in the broadband market, although minority advocates using the term often do not distinguish between these two cases.

In the third possible reason, the apparent relationship between black household concentration and access is spurious, due to omitted variables that are positively correlated 
with black concentration and negatively correlated with entry. An example of such an omitted variable is the quality of the telecommunications infrastructure in an area. Areas with high concentrations of black households may tend to have older infrastructure, and therefore higher costs of deploying DSL or cable modem networks.

To distinguish the first two (causal relationship) hypotheses from the third (spurious relationship) hypothesis, in a second set of estimations I include a host of socioeconomic and competitive controls. A major advantage that the large sample size of this study lends is the ability to control for many demand and cost variables that previous studies such as Gillett and Lehr (1999) and Gabel and Kwan (2001) omitted. Adding these extra variables removes the significance of most of the income and race coefficients, with a few exceptions discussed below.

To distinguish between profit-based discrimination and "taste for discrimination" based on racial composition of the area, I supplement the race variables with language variables. If carriers discriminate against minority areas, it is plausible that they would discriminate against both non-White race and non-English language usage. The evidence below shows, however, that non-English language usage tends to increase access availability. The case for preference-based discrimination is thus weak and any discrimination is more likely to be profit-based (probably based on expected demand).

In the rest of this section I explore implications of two features of the data: lack of subscribership data and using ZIP code level data. First, note that the data tell us nothing about the scale of entry within each area. Lack of information on the scale of entry is common in entry studies in the industrial organization literature, such as Bresnahan and Reiss (1987) and Berry (1992). Using a binary entry variable requires using a probit model, instead of using the number of subscribers in a tobit model. The estimates may be less precise in the probit than in the tobit, because there is less information in a binary 
variable (entry) than in a mixed continuous/discrete variable (subscribers), but will still be consistent if the model is correctly specified.

The data use ZIP code areas as the boundary for the unit of observation. While ZIP codes are an improvement over previous studies using larger areas, it is still true that broadband may not be available to all parts of the ZIP code area, which creates a potential difficulty in interpreting the results. Unequal availability within an area is not from carriers choosing individual households to which to offer broadband; once the local cable network or central office has been upgraded to offer broadband, the service is available to most subscribers in the service area. ${ }^{7}$ Instead, uneven availability within a ZIP code area is due to the irregular overlap with service areas. Thus, one consequence of using ZIP code areas is that broadband diffusion is overstated. To see this, note that from Table 1 , $70 \%$ of ZIP code areas in the sample have broadband access. However, various sources indicate that at the beginning of 2000 , cable modem service was available to only about one-third of households and DSL to only one-quarter of households in the U.S. ${ }^{8}$

Uneven availability within a ZIP code is a problem mostly in rural areas, where both service areas and ZIP code areas are large. This is one reason why the coefficients for the urban/rural indicators need to be interpreted with care, as is further discussed below. The coefficients for minorities would be biased due to unequal availability within an area only if minorities are consistently more likely to live in the uncovered part of the area. However, most minorities live in dense urban $\operatorname{areas}^{9}$ where the local exchange companies' central offices are close together, implying that if DSL is implemented at all, it would probably be available to all households in the area. For example, San Francisco has 24 ZIP code areas and 12 central offices, none of which are more than four miles from each other. DSL is typically available within 3.5 miles from the central office, resulting in potentially complete coverage if DSL were implemented at each central office. Cable modem service areas are even larger. 


\section{BROADBAND TECHNOLOGY}

Broadband access to the Internet comprises several steps. Consider DSL first. Starting from the Internet backbone (the left side of Figure 1), data flows through various networks and providers (the "middle mile") until it reaches the local exchange carrier's central office. In the "last mile" of the network, data passes over a DSL connection residing physically on the existing telephone line between the central office and the residential or business user's computer (the top right of Figure 1). Local exchange carriers have also leased high-speed access lines such as T-1 lines to residences and businesses for some time (middle right of Figure 1), but their high prices (at least $\$ 450$ per month) generally restrict them to high-volume business use. In cable data networks, data flows from the Internet through the cable company's headend (a cable service provider's version of the local exchange carrier's central office), and on to regional high-capacity data networks (the middle mile; bottom of Figure 1). In the last mile of a cable modem network, data travels through local fiber optic networks and finally over coaxial cable to the end-user (bottom right of Figure 2). Wireless and satellite carriers also offer broadband capability, although such firms typically focus on the business market and have small market share. Thus, for residential subscribers, cable modem service and DSL are currently the broadband options of choice (see Figures 2 and 3), with cable modems enjoying a three to one advantage.

The FCC (2000a) has found that Internet backbone and the middle mile facilities are generally adequate to provide broadband access. The last mile, the focus of this paper, is currently the limiting factor on the supply side of the market. 


\section{DATA}

The data for the study come from three major sources: the FCC, Census, and a telecommunications wire center database. A complete list of variables and summary statistics for the data are in Table 1.

\section{Broadband Availability Data and Summary}

The dependent variable, broadband availability from any source within a ZIP code, is taken from the FCC's (2000b) broadband survey reflecting conditions on 30 June 2000. The dependent variable covers all ZIP codes in the mainland states. ${ }^{10}$ Every facilitiesbased telecommunications carrier (incumbent and competitive local exchange carriers, wireless carriers, cable companies, and others) with more than 250 broadband lines in a given state is required to provide basic information about its operations in that state via the FCC survey. ${ }^{11}$ Carriers not meeting this reporting threshold may submit information voluntarily, and some did so. Note that this definition raises a selection issue: the smallest rural carriers may not show up in the survey even if they offer broadband, which in turn will mean that the ZIP codes from those areas may falsely be recorded as not having broadband access. The selection bias is likely to be minor because few broadband providers would fall below the threshold. For example, current market analysis indicates that unless there are about 200 lines in a DSL service area (which is much smaller than a whole state), the investment will not pay off (Paradyne 2000, 5-6). Nevertheless, the coefficients pertaining to rural areas, which may be served by small rural local exchange carriers with few customers, must be interpreted with this potential measurement error in mind.

The publicly available data do not indicate the type of company offering the service. In particular, DSL service is not distinguishable from cable modem service. The 
dependent variable in the estimations, then, is binary: whether there is at least one broadband customer in a ZIP code.

Table 1 shows that $70 \%$ of ZIP code areas in the sample have broadband access. These ZIP codes include $95 \%$ of the population of the U.S.; recall from the discussion in section II that this does not imply that broadband is available to $95 \%$ of households. See Figure 4 for a map depicting broadband availability.

\section{Market Characteristics Data}

Demand Variables. Factors influencing carriers' expected subscriber demand for broadband are captured by socioeconomic statistics at the ZIP code area level. The personal and household data are from the 1990 Census. ${ }^{12}$ The business data are also from the Census Bureau. ${ }^{13}$

Race and ethnicity variables include the percentages of black, Native American (including Eskimo, Aleut, etc.), Asian, and other (white is the excluded category) persons in the area, and the percentages of persons claiming Hispanic ethnicity. Closely related to race and ethnicity is language. Non-English-speaking groups may have lower demand for broadband if they perceive the Internet to consist largely of English-language content. On the other hand, non-English speakers may value the opportunities that the Internet affords to connect with similar speakers across the nation and world. I include variables for percentages of Spanish-speaking, Asian language-speaking, and other languagespeaking households, and also the percentage of "linguistically isolated" households, in which no one speaks English as a first language nor "very well" as a second language.

There are two income variables in the study: median income and the percentage of households below the poverty threshold. Next are controls for the size of the residential and business markets. The type of firm may also matter; in other studies manufacturing, FIRE (finance, insurance, and real-estate), and service-oriented (e.g., management consultants) firms have proven to be heavy users of telecommunications. I include the per- 
centage of firms of these types as controls. Since large firms may have higher demand for broadband, I include two measures of firm size: log average employment per firm and the percentage of firms with fewer than 50 employees.

Households are categorized as inside an urbanized area, urban but outside an urbanized area (mostly smaller towns), rural non-farm, or rural farm. Taking urban/outside urbanized area as the excluded variable, I include variables for the percentage of households of each of the other types, where the rural areas are split into those served by Bell Operating Companies and those served by other local exchange carriers. Rural non-Bell carriers are often characterized as technological laggards (although their industry group refutes this assertion [NECA 1999]), so Bell Operating Companies may act differently in rural areas than other carriers.

I include variables describing the age profile of an area: the percentage of individuals in various age groups, relative to the excluded group of seniors (age 65 and above). Controls for education levels include percentages of persons whose highest degree is a high school diploma, a four-year college degree, and a graduate degree. Commuting time will be positively correlated with broadband demand, if telecommuting is more popular in areas where commutes are longer. I include variables for the percentage of employed individuals who work at home and who have commutes of various lengths (0-15 minutes is the excluded category). Other demographic controls included are the percentage of females in the area, fraction of households with children under 18 years, and fraction of households with a telephone.

Given the focus on entry, and not competition after entry, I follow authors such as Berry (1992) in omitting price variables. ${ }^{14}$ The demand variables described above provide the information that potential entrants use to determine their price, should they decide to enter. Including these demand variables in the estimations therefore proxies for the expected post-entry price and profit. 
Costs. Various studies and industry sources suggest that relevant cost considerations for broadband deployment are fixed costs, subscriber density, and the vintage of the telecommunications infrastructure. ${ }^{15}$ The fixed costs are from installing the necessary equipment in the wire center to enable DSL ${ }^{16}$ or in the headend to enable cable modem service. To the extent that average fixed costs vary among regions only through the number of subscribers (the denominator), and that subscription is a function of demographic variables, the inclusion of demographic variables will indirectly control for difference in average fixed costs.

Costs are lower in areas where subscriber density is higher. In denser areas the same investment at the wire center (for DSL) or the middle mile network (for cable modem service) reaches more potential subscribers. Also, in areas with low subscriber density, the average DSL customer is farther from the central office and requires stronger (and therefore more expensive) carrier signals to be sent. I include two density measures: the number of occupied housing units with telephone access and population, both per square kilometer. The former may be a better measure for DSL deployment costs, since DSL requires a phone line, and the latter may be better for cable modem deployment costs.

The older the vintage of the local telecommunications and cable networks, the more expensive is broadband implementation. ${ }^{17}$ Lacking direct data, I proxy the age of installed networks with the median age of the housing structures in the area. A final cost variable is the cost of connecting to the nearest Internet backbone. In rural areas without nearby access, connection costs may be higher than in urban areas. Also, rates for connecting to the Internet backbone tend to be lower in urban areas, due to competition among backbone access providers. Data on backbone access cost is not readily available, and so the rural and urban dummy variables will absorb systematic difference in these costs among regions. A National Telecommunications and Information Administration 
and Rural Utilities Service $(2000,9)$ study, however, downplays the importance of Internet backbone availability as an important difference between urban and rural areas, so perhaps these cost data are not crucial.

Local telecommunications competition. While cable companies mostly still enjoy monopolies within their service areas, local telecommunications competition has started to spring up since the passage of the Telecommunications Act of 1996. Anecdotal evidence from the industry suggests that incumbent local exchange carriers are more likely to offer advanced services in areas in which they face competition. Some facilities-based competitors offer DSL themselves (and therefore appear in the dependent variable).

The FCC makes available a list of ZIP codes in which there is local competition. In one specification I include a dummy for the presence of at least one competing local exchange company (CLEC) in the area. That specification models jointly the availability of broadband and local telephony competition (see the appendix).

Telecommunications Carriers' Operating Areas. Industry reports suggest that some Bell carriers were more aggressive than others in deploying DSL. Indicator variables for the presence of one of the four remaining Bell firms as the incumbent local exchange carrier in the ZIP code are included: BellSouth, Qwest (fka U.S. West), SBC (Southwestern Bell Telephone, Pacific Bell, Nevada Bell, and Ameritech), Verizon (fka Bell Atlantic and NYNEX). ${ }^{18}$ The excluded dummy is all non-Bell carriers. ${ }^{19}$

\section{THE EVIDENCE FOR UNEQUAL AVAILABILITY OF BROADBAND}

Here I present two sets of estimations. In Table 2, simple probit estimations including only race, income, and geographic variables are presented. Table 3 includes expanded estimations investigating the impact of including cost and demand variables omitted from the simpler estimations. 
Consider the first estimation reported in Table 2, with race, ethnicity, and geographic variables only (urban/rural indicators, and Bell territory and state fixed effects). The results accord with the common perception of the Digital Divide: the coefficients for blacks, Native Americans, and Hispanics and the rural variables are all negative and significant. The coefficient on the fraction of Asians in the area is significantly positive. Before imputing causality to these findings, however, note that once income variables are added (last columns of Table 2), the race and ethnicity coefficients lose all significance. Apparently income is an omitted variable in the first estimation that leads to spurious correlation between the race variables and broadband access. The results below show that once additional omitted variables are included, the significance of the coefficient on income is also lost.

Table 3 has the results of three estimations, expanded to include the full set of demand and cost variables. The first estimation leaves out the language variables and the CLEC presence variable. The second adds the language variables, and the third includes all variables. $^{20}$ The coefficient, average marginal effect on the mean, and robust standard error $^{21}$ are reported for each variable. The fit appears to be quite good for cross-sectional data; the $R^{2}$ is about 0.45 and many of the estimated coefficients are statistically significant at the one percent level. The results from the models are remarkably consistent; none of the statistically significant coefficients changes sign between estimations. ${ }^{22}$ Except when specifically discussing race, ethnicity, and language, below I discuss the results of the second estimation (language variables but no CLEC variable). At the end of this section, I touch on the estimation with the CLEC presence included.

\section{$\underline{\text { Race and Ethnicity }}$}

The race, ethnicity, and language coefficients in the second estimation (middle columns of Table 3) reveal interesting countervailing effects. The non-white race and Hispanic ethnicity coefficients are negative (with the exception of percentage black house- 
holds) but the non-English language coefficients are positive. These results for language may bolster theories, current in other social sciences, that individuals use the Internet to seek out a community of interest (Elkins 1997). If so, then carriers may expect higher demand for broadband in areas with more non-English speakers and be more likely to implement access. As discussed in section II, positive non-English language effects imply that preference-based discrimination against minorities is unlikely.

The net effects from race and language can go either way. Table 4 illustrates the net effects of the race and language variables, presenting the fraction of observations for which various groups of race-related variables lead to a decreased probability of availability, ceteris paribus. If carriers' profit considerations adversely affect minorities, then the net effects of these race-related variables will be negative. For example, the first row summarizes the net effects from the \% Asian, \% language Asian, and the Asian:language Asian and Asian/linguistically isolated interactions, when calculated at sample values. In $95 \%$ of the observations, the net impact of these Asian-specific variables decreases access probability (compared to white, English-speaking households). When weighted by the Asian population in the area (the next column), the figure drops to about $74 \%$. The figure drops further to about $54 \%$ if statistical significance is required of the evidence. Thus, adverse access possibilities for Asians appear to be present in areas where $54 \%$ of the Asian population lives. Native Americans are the other racial group that suffers nearly universal lower probability of access than white, English-speaking households. The evidence for unequal access is statistically strong in areas in which $89 \%$ of Native Americans live. Thus, for these two groups, the appearance of unequal availability warrants further investigation. However, the evidence for unequal access is weak for any other group. The black, Hispanic, and other-race net effects are significantly negative in virtually no areas. The net effect from all race and language variables combined (the last row in the table) is significantly negative in areas where only $13.5 \%$ of non-whites live. 
The race, ethnicity, and language variables are highly correlated, and one may suspect that multicollinearity is driving these results. The first estimation in Table 3, in which the language variables are omitted, lends evidence that this is not the case. The results show that removing the language variables does not result in significant race and ethnicity coefficients, except for Native Americans. Therefore, this estimation further corroborates that race and ethnicity generally play little role in the broadband entry decision.

Here I further explore unequal broadband access opportunities for Asians and Native Americans, the groups for which the pessimists' case is strongest. The specifications above constrain the coefficients on the racial variables to be constant, which may not be the case. To explore this possibility, I estimate a generalized additive model (GAM) in which \% Asian and \% Native American enter the broadband equation nonparametrically. In particular, the model for the observed binary availability variable y (taking value 1 if broadband is available, zero if not) is

$$
\begin{gathered}
y^{*}=x^{\prime} \beta+f\left(z_{\text {natamer }}\right)+g\left(z_{\text {asian }}\right)+\varepsilon_{i} \\
y=1 \text { if } y^{*}>0,0 \text { otherwise }
\end{gathered}
$$

where $\mathrm{x}$ includes all the variables in the first column of Table 3 (except interaction terms), and the z's are the $\%$ Native American and $\%$ Asian variables. The error $\varepsilon_{\mathrm{i}}$ is assumed to be i.i.d. standard Normal; if functions $f$ and $g$ in (1) were linear, the model would be a standard probit. Instead, f and g are nonparametric smoothing functions (cubic B-splines). ${ }^{23}$ The resulting partial fits are shown in Figure 5. When the fitted curve slopes down in these graphs, the marginal effect of the variable on availability is negative. For comparison, if the variable were constrained to enter the model in linear form, the partial fit would be a line with slope equal to the estimated coefficient.

If Asians and Native Americans faced consistent discrimination (of any sort), the fitted curves would be negatively sloped everywhere. However, the effects of these vari- 
ables are clearly not monotonic. In only $50 \%$ of the areas does $\%$ Asian have a negative effect. When weighted by Asian population, this figure is $72 \%$. For \% Native American, the effect is negative in only $12 \%$ of areas ( $44 \%$ when weighted by Native American population), although that subset includes the areas with the highest concentrations (mainly reservations). ${ }^{24}$ So even without taking into account the countervailing effects of language, ${ }^{25}$ the evidence indicates that unequal availability for Asians and Native Americans is not uniform across areas. In fact, in $50 \%$ of the areas, having marginally more Asians increases the probability of broadband access - this is probably why the linear coefficient for \% Asian was positive in the simple estimations in Table 2. Similarly, in $88 \%$ of the areas, having marginally more Native Americans increases the probability of broadband access.

\section{$\underline{\text { Income }}$}

There is no statistically significant evidence for unequal access based on income. The income coefficients have the expected signs - access is more likely the higher is median income and less likely the more households are in poverty_-but neither is significant. $^{26}$ The reason why the income coefficient was significant in the simple estimation in Table 2 but not here is again likely to be due to omitted variables. Wealthier areas are likely to have lower costs of providing broadband, due to better infrastructure, higher phone density, and higher population density. It appears carriers' lower costs may induce them to roll out broadband earlier in wealthier locations, not necessarily income per se.

\section{$\underline{\text { Rural Location }}$}

The geographic coefficients are all negative (compared to "urban but outside urbanized area"). That rural and inner city areas lag in access has been found in other studies (FCC 2000b); this estimation shows that this result persists even after controlling for demographics. The areas least likely to have access are rural non-farm areas served by a 
non-Bell local exchange carrier. Access probabilities are statistically indistinguishable between rural areas served by Bell Operating Companies and other local exchange carriers-evidence that small rural carriers are not lagging behind the Bell Operating Companies, controlling for other factors. Given the potentially poor measurement of the entry variable in rural areas due to the reporting threshold, however, these conclusions remain tentative.

\section{Effects Of Other Market Characteristics}

The market size coefficients for households and firms are positive and significant. The marginal effect of 0.034 for log number of households means that if the number of households nearly tripled, there would be about a three and a half percentage point increase in the probability of broadband access. ${ }^{27}$ The marginal effect of the size of the business market (number of firms) is about twice as strong.

Of the significant age coefficients, each age group's effect is positive compared to the excluded senior group. Similarly, the education coefficients are all positive, compared to the excluded group lacking a high school degree or equivalent. The commuting distance coefficients have the expected signs for the most part. A larger fraction of workers at home increases access likelihood. For commuters, the longer the commute, the higher the access probability (with the exception of the longest commuters, one hour plus).

The fraction of households with a telephone has a nonmonotonic effect on access. Since DSL requires a phone line to function, it is not surprising that in the region where most of the observations lie, the interval (0.925-1.0), the marginal effect is positive. Of the business coefficients, only the fraction of small firms — a negative effect — is significant.

Exploratory analysis revealed that the cost variables have nonmonotonic relationships to broadband access. In the estimations in Table 3, I used linear spline functions for the cost variables. The ordinates of the knots were chosen based on visual inspection of 
nonparametric partial fits; the knots are close to the first and third quartiles in each case. Phone density has the expected positive sign in the region in which most of the data appear (>0.4). None of the population density coefficients is significant, probably because the set of urban and rural dummy variables are closely related. The age of housing structures, as a proxy for network infrastructure vintage, has the expected negative sign in the ranges up to 17.5 years and greater than 35 years, but not in the middle range.

All Bell Operating Company indicators are significant and positive, probably because the Bell companies are rolling out broadband faster than other local exchange carriers, even after controlling for differences in demand characteristics among regions. ${ }^{28}$

\section{Local Telecommunications Competition}

The third estimation in Table 3 contains the CLEC presence variable. Since CLEC presence is endogenous, I estimate the CLEC and broadband entry decisions jointly in a bivariate probit model in which CLEC presence appears as an explanatory variable in the broadband equation and as a dependent variable in a second equation. Further details are in the Appendix. The table contains the coefficients from the broadband entry equation only. The estimated effect of competition in local telephony is relatively large but statistically insignificant. The marginal effect is 0.267 , implying that when there is local competition the probability of broadband access rises by 26.7 percentage points. The other estimates from the broadband entry part of the model, including those for race and income, are very close to those from the previous estimation.

\section{IMPLICATIONS}

This study contributes a better understanding of the determinants of the availability of broadband Internet access. Notwithstanding that the market is well on its way toward full diffusion on the supply side, there has been concern at the FCC and elsewhere about broadband availability for minority, low income, and rural households. Careful research 
into these issues is warranted given the federal mandate to deploy broadband to "all Americans" and the demonstrated willingness of the FCC to spend significant resources to encourage universal service. ${ }^{29}$

The results above give no statistically significant evidence of unequal availability based on income. There is some evidence for unequal availability for Asians and Native Americans; the case to be made for discrimination (profit-based or otherwise) against any other racial or ethnic group is very weak. Even for Asians and Native Americans, the evidence for unequal availability is inconsistent across the range of the variables. In particular, for both groups the nonparametric analysis shows that there are many ranges of concentration that exhibit positive marginal effects on broadband availability. Finally, after noting that Asian households are more likely to subscribe to broadband than any other racial group (NTIA, 2000), Native Americans remain the sole group of possible concern. Race-focused rhetoric about the broadband Digital Divide appears to be largely unwarranted, at least on the supply side.

More important determinants of broadband availability are rural location and demand characteristics such as age, education, commuting time, sex, and size of businesses in the area. Therefore, universal service policies (if deemed necessary at all) should focus less on the supply side (with the possible exception of rural areas) and more on the demand side, perhaps through targeted subsidies to lower-income individual subscribers and small businesses.

The implementation of new technology may change the course of future broadband access policy discussions. For example, DirecPC and StarBand, two satellite broadband Internet access providers, began nationwide service in 2001 (after the time frame of the data examined here). Theoretically, any household with a clear view of the southern sky could access these services. Satellite broadband is currently much more expensive than 
DSL or cable modem service, ${ }^{30}$ and so the question switches from availability vs. unavailability to low-price access vs. high-price access.

Further study of broadband diffusion will be aided by the FCC's ongoing data collection. The FCC broadband survey is given every six months, which will allow panel data methods to be used in future explorations. Given that income and racial composition vary much more over the cross-section than over time, however, panel data may not add much to the investigation.

\section{REFERENCES}

Becker, Gary S. The Economics of Discrimination. 2nd. ed. Chicago: U. of Chicago Press, 1971.

Berry, Steven T. "Estimation of a Model of Entry in the Airline Industry." Econometrica, 60(4), 1992, 889-917.

Bresnahan, Timothy F., and Peter C. Reiss. "Do Entry Conditions Vary Across Markets?" Brookings Papers in Economic Activities, 18, 1987, 833-882.

Cooper, Mark. "Disconnected, Disadvantaged, and Disenfranchised: Explorations in the Digital Divide.” Consumers Union and Consumer Federation of America Joint Report, <http://www.consumersunion.org/pdf/disconnect.pdf>, October 11, 2000.

Elkins, D.J. “Globalization, Telecommunication, and Virtual Ethnic Communities.” International Political Science Review, 18(2), 1997, 139-152.

Faulhaber, Gerald R. and Christiaan Hogendorn. "The Market Structure of Broadband Telecommunications.” Journal of Industrial Economics, 48(3), 2000, 305-329.

Federal Communications Commission. Deployment of Advanced Telecommunications Capability: Second Report. FCC 00-290.

<http://www.fcc.gov/Bureaus/Common_Carrier/Orders/2000/fcc00290.pdf>, August 2000a. 
Federal Communications Commission, Common Carrier Bureau, Industry Analysis Division. High-Speed Services for Internet Access: Subscribership as of June 30, 2000. $<$ http://www.fcc.gov/Bureaus/Common_Carrier/Reports/FCCState_Link/IAD/hspd1000.pdf>, October 2000b.

Federal Communications Commission, Federal-State Joint Board on Universal Service. Universal Service Monitoring Report. <http://www.fcc.gov/Bureaus/Common_Carrier/Reports/FCCState_Link/Monitor/mrs01-0.pdf>, October 2001.

Gabel, David, and Florence Kwan. "Accessibility of Broadband Telecommunication Services by Various Segments of the American Population.” In Communications Policy in Transition: the Internet and Beyond, edited by B. M. Compaine and S. Greenstein. Cambridge: MIT Press, 2001, 295-320.

Gillett, Sharon Eisner and William Lehr. "Availability of Broadband Internet Access: Empirical Evidence.” Manuscript, September 1999.

Hastie, Trevor and R.J.Tibshirani. Generalized additive models. London; New York: Chapman and Hall, 1990.

Hausman, Jerry A., J. Gregory Sidak, and Hal J. Singer. “Cable Modems and DSL: Broadband Internet Access for Residential Customers." American Economic Review, 91(2), 2001, 302-307.

Maddala, G. S. Limited-Dependent and Qualitative Variables in Econometrics. Econometric Society Monographs, Cambridge: Cambridge University Press, 1983.

Madden, Gary, Scott J. Savage, Grant Coble-Neal, Paul Bloxham. “Advanced Communications Policy and Adoption in Rural Western Australia.” Telecommunications Policy, 24(4), 2000, 291-304.

National Association of State Telecommunications Directors. "Our Digital Nation: Separate and Unequal?" NASTD Backgrounder, 4(5), 2000, 1-4. 
National Exchange Carrier Association. Access Market Survey of NECA's Traffic Sensitive Pool Members, Keeping America Connected: the Broadband Challenge. December 1999.

National Telecommunications and Information Administration. Falling Through the Net: Toward Digital Inclusion: A Report on Americans' Access to Technology Tools. <http://www.ntia.doc.gov/ntiahome/fttn00/contents00.html>, October 2000.

Olson, David C. "Open Access on Internet High Seas: Where the FCC is Loathe to Sail.” Journal of Municipal Telecommunications, 1(1), <http://munitelecom.org/v1il/Olson.html>, April 1999.

Paradyne Corp. The DSL Sourcebook. <http://www.paradyne.com/sourcebook_offer/sb_1file.pdf〉, 2000.

Prieger, James E. “The Supply Side of the Digital Divide: Is There Redlining in the Broadband Internet Access Market?" Working Paper 01-16, AEI-Brookings Joint Center for Regulatory Studies, December 2001.

Public Utilities Commission of Nevada. Order in Docket No. 99-12033 and Docket No. 00-4001. November 9, 2000.

Tootell, Geoffrey M.B. "Redlining in Boston: Do Mortgage Lenders Discriminate against Neighborhoods?" Quarterly Journal of Economics, 111(4), 1996, 1049-79.

Trujillo, Solomon D. Testimony Before The U.S. Senate Committee On Commerce, Science And Transportation. <http://www.senate.gov/ commerce/hearings/0413tru.pdf>, April 13, 1999.

\section{Appendix}

This appendix contains details on the third estimation presented in Table 3. The model is a bivariate probit with dependent variables broadband presence and CLEC presence in the ZIP code, and correlation parameter $\rho$. The CLEC presence variable also appears as 
a right hand side variable in the broadband equation. This is Maddala's (1983, p.122) Model 6, which requires that the CLEC presence equation contain at least one variable that is not in the broadband equation for identification when $\rho \neq 0$. I estimated the model by MLE.

The instrument in the CLEC equation is the proxy cost for local telecommunications service in the local exchange area, as calculated by the FCC's Hybrid Cost Proxy Model (HCPM) in January 2000. The HCPM is an economic engineering model that calculates the cost of providing local telecommunications service using efficient technology, given an area's geographic terrain and subscriber density. Proxy costs are not available from the model for about one-third of the wire centers (mostly for smaller carriers); in these cases I used the proxy cost of the nearest wire center for which cost was available. Wire center boundaries were matched to ZIP code areas as described in the text for the Bell Operating Company indicator variables. Proxy costs should be highly correlated with competitors' entry decisions, and indeed are significant in the CLEC equation. The proxy cost coefficient is insignificant if the variable is added to a univariate estimation of the broadband equation when CLEC presence is already included, which lends credibility to excluding proxy costs from the broadband equation.

Only the coefficients from the broadband equation are reported in Table 3 . The variables included in the CLEC equation are state fixed effects, proxy cost, Bell Operating Company indicators, and the market size, geographic composition, and income variables. The estimate of $\rho$ is 0.13 , with a $p$-value of 0.047 . The $p$-value of the likelihood ratio test for $\rho=0$ is 0.037 , so it is likely that the CLEC presence variable is endogenous in the broadband equation.

\section{Captions for Figures:}


Figure 1: A Stylized Depiction of DSL and Cable Modem Internet Access

Figure 2: Choice of Broadband Technology by Residences and Small Businesses

Figure 3: Choice of Broadband Technology by Larger Businesses

Figure 4: Broadband Availability by Number of Providers of Any Type as of June 2000.

Figure 5: Partial nonparametric fits of the variables \% Asian population and \% Native American population

\section{Notes for Figures:}

To be placed at the bottom of the figure:

\section{For Figure 5:}

Figure contains the partial fits from nonparametric cubic B-splines. Positive slopes imply positive marginal effects of the variable on broadband availability. Ticks at bottom of plots mark the sample data. Abscissae are calibrated so the $y$ value is zero at the mean $\mathrm{x}$ in the sample.

\section{Notes}

\footnotetext{
* An early version of this article was presented under the title "Who's Jumping on the Broadband Wagon" at the 2001 WEAI Annual Meeting. A later version circulated as Prieger (2001). I gratefully acknowledge a grant from the Institute of Governmental Affairs at UC Davis that supported this work. I thank Alyson Ma, Neill Norman, and Shehzad Ibrahim for research assistance.

Author: Assistant Professor, Department of Economics, University of California, One Shields Avenue, Davis, CA 95616. Phone (530) 752-8727, Fax (530) 752-9382, E-mail jeprieger@ucdavis.edu.
} 
${ }^{1}$ See Cooper (2000) and National Telecommunications and Information Administration (2000).

2 "The problem is not that the disconnected do not participate in physical space, it is that they cannot participate in cyberspace" (Cooper, 2000). "[Broadband is] not being deployed to all Americans because of the realities of the marketplace, which by its nature cannot serve all customers equally.... Rural, minority, low-income populations and people with disabilities are some of those groups who are not able to fully access the technology." (comments filed by The Alliance for Public Technology in the $2^{\text {nd }}$ FCC Notice of Inquiry Concerning the Deployment of Advanced Telecommunications Capability, CC Dkt No. 98-146, March 2000). See also NASTD (2000).

${ }^{3}$ See Olson (1999) and Trujillo (1999). Redlining originally referred to the practice of a lending institution denying home loans to households in certain areas of a community. It has come to be used by some advocates as a pejorative to refer to price or availability discrimination that is correlated with race or income in any line of business.

${ }^{4}$ Pending bills allow Bell carriers more flexibility in carrying broadband traffic across regulatory boundaries and require them to deploy broadband capability in all their local exchanges within five years (H.R. 1542), attempt to strengthen antitrust laws to open telecommunications markets (including broadband) to competition (H.R. 1697, 1698, and 2120), and provide tax credits (S. 88, S. 150, S. 426, H.R. 267, H.R. 1415) or grants and loans (S. 428, H.R. 1416, H.R. 1697) to promote broadband deployment. ${ }^{5}$ See sec. 706 of the 1996 Telecommunications Act, Pub. L. 104-104, Title VII, Feb. 9 , 1996, 110 Stat. 153.

${ }^{6}$ I will use the terms "wire center" and "central office" interchangeably. They are the primary points at which local exchange carriers connect subscribers to the public switched telephone network. 
${ }^{7} \mathrm{FCC}(2000 \mathrm{a})$, at 81.

${ }^{8}$ See FCC (2000a) at 195 and footnote 236.

${ }^{9} 86.1$ percent of blacks and 91.2 percent of Hispanics live in urban areas.

${ }^{10}$ ZIPs that do not correspond to a geographic area (P.O. boxes and single-entity ZIPs) are excluded.

${ }^{11}$ Broadband is defined in the survey as transmission speed in excess of $200 \mathrm{kbps}$ in at least one direction. The FCC considers a carrier to be "facilities based" if it provides broadband access over its own local loop, or over unbundled network elements (UNEs) or leased lines that it obtains from other carriers and equips as broadband (FCC, Instructions for Form 477, 2001).

12 Bureau of the Census, Census of Population and Housing, 1990: Summary Tape File 3 CD-ROM.

${ }^{13}$ Bureau of the Census, ZIP Code Business Patterns CD-ROM, 1997 data.

${ }^{14}$ Prices are not observed if entry does not occur. Even if prices are observed, they may not vary much among areas. As of November 2001, each of the Bells offers DSL service for the same price everywhere in their service regions. Furthermore, all of the companies except Qwest charge \$50/month for basic DSL. Cable modem prices may show more regional variation (Hausman, Sidak, and Singer [2001]).

15 See Faulhaber and Hogendorn (2000) and Gabel and Kwan (2001), for example. ${ }^{16}$ Chiefly, a DSLAM (DSL Access Multiplexer), a mechanism at the wire center that links many end-user's DSL connections to a single high-speed ATM line. The DSLAM involves both fixed and variable costs.

${ }^{17}$ In older networks, frayed insulation or poorly spliced loops may degrade transmission quality. Other problems include load coils (devices that were used to enhance the quality of voice traffic over copper lines) and bridged taps (any portion of the local loop that is 
not in the direct path between the central office and the end user's terminating equipment). DSL requires these coils and taps to be removed on a line-by-line basis, which is costly. Best-practice local loop design for the last 20 to 30 years has excluded excessive bridge taps and load coils (Public Utilities Commission of Nevada, Order in Docket Nos. 99-12033 and 00-4001, 9 November 2000, at 46, and FCC [2000a] at 39).

${ }^{18}$ Given the rapid changes in the BOCs' coverage areas due to mergers, the variables reflect only the traditional BOC service areas (for example, Southern New England Telephone's area is not included with SBC, nor is GTE's with Verizon).

${ }^{19}$ To construct the Bell Operating Company service area variables, ZIP code areas were matched to wire center areas. These areas overlap irregularly; wire center boundaries tend to be larger than ZIP code areas. I matched the population-weighted geographic centroid of the ZIP code area to the closest wire center location. The centroids are from OSEDA (<http://www.oseda.missouri.edu/jgb/ZIP.resources.html>). The wire center locations are from Stuff Software's May 2001 C.O. Finder! database.

${ }^{20}$ A likelihood ratio test convincingly rejects specifications without state fixed effects.

${ }^{21}$ White's standard errors are robust to heteroskedasticity, although the coefficient estimates are biased in that case. The main conclusions of the paper do not change if the usual standard errors are employed.

${ }^{22}$ Similarly, none of the statistically significant coefficients change sign if a logit specification is used instead of probit.

${ }^{23}$ The model (Hastie and Tibshirani, 1990) is estimated with the gam command in SPlus, where the s smoother is used for the z's.

${ }^{24}$ It is not surprising that Indian reservations lag in broadband access: only $47 \%$ of households on reservations have telephone service. The FCC currently has initiatives in 
place to extend universal service to reservations (FCC, Consumer Facts: Increasing Telephone Service in Indian Country, 3 August 2001).

${ }^{25}$ The generalized additive model does not allow inclusion of interaction effects.

${ }^{26}$ Inclusion of the population density and urban/rural variables may obscure the effects of income, if low-density, rural areas have lower incomes. However, even when these variables are removed, the income and poverty variables remain insignificant.

${ }^{27}$ The marginal effect of a variable that is in logs corresponds to the effect of multiplying the variable in levels by $e(\cong 2.7)$.

${ }^{28}$ An alternative explanation (not one that survives Occam's Razor) is that other broadband carriers (cable modem, wireless, etc.) are entering the Bells' territories to establish market presence in anticipation of future competition for broadband customers.

${ }^{29}$ Despite telephone penetration of over $94 \%$, over $\$ 4.5 \mathrm{~B}$ was collected for universal service funding in 2000 (FCC, 2001).

${ }^{30}$ For example, Earthlink's DirecPC service has $\$ 600$ in start-up costs for the subscriber, and a $\$ 70 /$ month fee. Most of the Bells offer DSL service for $\$ 50 /$ month or less and waive the installation and equipment fees (prices as of February 2002). 
Table 1

Summary Statistics of the Data

\begin{tabular}{|c|c|c|c|c|c|}
\hline Variable & Mean & $\begin{array}{l}\text { Standard } \\
\text { Deviation }\end{array}$ & Variable & Mean & $\begin{array}{l}\text { Standard } \\
\text { Deviation }\end{array}$ \\
\hline Dependent Variable & & & $\%$ language asian & 0.005 & 0.013 \\
\hline Broadband availability (1=yes) & 0.708 & 0.454 & $\%$ other language & 0.045 & 0.058 \\
\hline Independent Variables & & & \% language Spanish & 0.037 & 0.072 \\
\hline$\%$ age $<13$ yrs & 0.205 & 0.052 & $\%$ linguistically isolated & 0.016 & 0.042 \\
\hline$\%$ age $14-18$ yrs & 0.071 & 0.025 & $\%$ manufacturing firms & 0.004 & 0.064 \\
\hline$\%$ age $19-24$ yrs & 0.074 & 0.044 & $\%$ native american & 0.011 & 0.055 \\
\hline$\%$ age $25-29$ yrs & 0.074 & 0.031 & $\%$ other race & 0.018 & 0.057 \\
\hline$\%$ age $30-34$ yrs & 0.083 & 0.027 & $\%$ phone in household & 0.929 & 0.076 \\
\hline$\%$ age $35-39$ yrs & 0.078 & 0.027 & \% rural (farm), BOC telco & 0.014 & 0.048 \\
\hline$\%$ age $40-49$ yrs & 0.127 & 0.037 & $\%$ rural (farm), non-BOC telco & 0.055 & 0.109 \\
\hline$\%$ age $50-64$ yrs & 0.143 & 0.047 & \% rural (non-farm), BOC telco & 0.224 & 0.373 \\
\hline$\%$ asian & 0.010 & 0.029 & $\%$ rural (non-farm), non-BOC telco & 0.375 & 0.426 \\
\hline$\%$ below poverty line & 0.146 & 0.100 & $\%$ services firms & 0.043 & 0.204 \\
\hline$\%$ black & 0.072 & 0.159 & $\%$ small firms (<50 employees) & 0.988 & 0.106 \\
\hline$\%$ college degree & 0.102 & 0.076 & $\%$ work at home & 0.056 & 0.072 \\
\hline$\%$ commute $15-29$ minutes & 0.323 & 0.124 & average employment per firm & 2.078 & 0.785 \\
\hline$\%$ commute $30-44$ minutes & 0.172 & 0.095 & BellSouth & 0.096 & 0.295 \\
\hline$\%$ commute $45-59$ minutes & 0.064 & 0.057 & households (log) & 7.056 & 1.582 \\
\hline$\%$ commute $60+$ minutes & 0.060 & 0.059 & median income (log) & 0.147 & 0.381 \\
\hline$\%$ female & 0.505 & 0.038 & number of firms (log) & 4.100 & 1.862 \\
\hline$\%$ FIRE firms & 0.000 & 0.030 & phone density (log) & 2.449 & 2.335 \\
\hline$\%$ graduate degree & 0.052 & 0.055 & population density (log) & 3.529 & 2.303 \\
\hline$\%$ high school degree & 0.590 & 0.127 & Qwest (U.S. West) & 0.068 & 0.252 \\
\hline$\%$ hispanic & 0.044 & 0.114 & SBC-PacBell-Ameritech & 0.164 & 0.370 \\
\hline$\%$ inside urbanized area & 0.247 & 0.415 & structure age (years) & 28.372 & 12.268 \\
\hline$\%$ kids in household & 0.356 & 0.099 & Verizon (Bell Atlantic-NYNEX) & 0.170 & 0.376 \\
\hline
\end{tabular}

Note: $B O C$ is Bell Operating Company. All percentages expressed as fractions. 
Table 2

Probit Estimations for the Availability of Broadband Service Within a ZIP Code Area

\begin{tabular}{|c|c|c|c|c|}
\hline \multirow[b]{2}{*}{ Variable } & \multicolumn{2}{|c|}{$\begin{array}{c}\text { Probit } \\
\text { (race and ethnicity variables) }\end{array}$} & \multicolumn{2}{|c|}{$\begin{array}{c}\text { Probit } \\
\text { (race, ethnicity, and income variables) }\end{array}$} \\
\hline & Coefficient & Robust s.e. & Coefficient & Robust s.e. \\
\hline \multicolumn{5}{|l|}{ Race and ethnic composition } \\
\hline$\%$ black & -0.438 & $0.083^{* \star *}$ & 0.079 & 0.090 \\
\hline$\%$ Native American & -0.748 & $0.158^{\star \star *}$ & -0.150 & 0.164 \\
\hline$\%$ Asian & 3.661 & $1.365^{\star * *}$ & 1.540 & 1.015 \\
\hline$\%$ other race & -0.126 & 0.330 & -0.101 & 0.343 \\
\hline \% Hispanic & -0.539 & $0.174^{\star \star \star}$ & -0.114 & 0.180 \\
\hline \multicolumn{5}{|l|}{ Income and poverty } \\
\hline median income (log) & & & 0.752 & $0.062^{* * *}$ \\
\hline$\%$ below poverty line & & & -0.202 & 0.207 \\
\hline Geographic composition & & $0.070^{* * *}$ & & \\
\hline$\%$ rural (non-farm), BOC telco & -1.711 & $0.075^{\star * *}$ & -1.629 & $0.071^{\star * *}$ \\
\hline$\%$ rural (non-farm), non-BOC telco & -2.071 & $0.231^{* * *}$ & -1.957 & $0.075^{\star * *}$ \\
\hline$\%$ rural (farm), BOC telco & -3.499 & $0.123^{* * *}$ & -3.362 & $0.233^{\star * *}$ \\
\hline$\%$ rural (farm), non-BOC telco & -3.364 & & -3.230 & $0.123^{\star * *}$ \\
\hline Bell Operating Companies & & $0.096^{*}$ & & \\
\hline BellSouth & 0.145 & $0.125^{\star * *}$ & 0.096 & 0.098 \\
\hline Qwest (U.S. West) & 0.963 & $0.086^{\star *}$ & 0.941 & $0.127^{* * *}$ \\
\hline SBC-PacBell-Ameritech & 0.167 & $0.119^{\star * *}$ & 0.152 & $0.087^{* *}$ \\
\hline Verizon (Bell Atlantic-NYNEX) & 1.411 & $0.196^{* * *}$ & 1.477 & $0.120^{\star * *}$ \\
\hline Intercept & 1.951 & $0.083^{\star * \star}$ & -6.599 & $0.790^{\star * *}$ \\
\hline Log likelihood & \multicolumn{2}{|c|}{$-10,860.8$} & \multicolumn{2}{|c|}{$-10,636.5$} \\
\hline Kullback-Leibler $\mathrm{R}^{2}$ & \multicolumn{2}{|c|}{0.349} & \multicolumn{2}{|c|}{0.363} \\
\hline
\end{tabular}

Notes: 27,623 observations. Dependent variable is 1 if there is at least one broadband customer in the ZIP code, 0 if not. Both estimations include state fixed effects. The sample includes all states except AK, HI, DC, and DE (latter two dropped because there is no variation in the dependent variable). BOC is Bell Operating Company. See text for variable definitions. 
Table 3

Probit Estimations for the Availability of Broadband Service Within a ZIP Code Area

\begin{tabular}{|c|c|c|c|c|c|c|c|c|c|}
\hline \multirow[b]{2}{*}{ Variable } & \multicolumn{3}{|c|}{$\begin{array}{c}\text { Probit } \\
\text { (no language variables) }\end{array}$} & \multicolumn{3}{|c|}{$\begin{array}{c}\text { Probit } \\
\text { (with language variables) }\end{array}$} & \multicolumn{3}{|c|}{$\begin{array}{l}\text { Bivariate Probit (broadband } \\
\text { entry and CLEC presence) }\end{array}$} \\
\hline & Coef. & $\begin{array}{c}\text { Marginal } \\
\text { effect }\end{array}$ & $\begin{array}{c}\text { Robust } \\
\text { s.e. }\end{array}$ & Coef. & $\begin{array}{c}\text { Marginal } \\
\text { effect }\end{array}$ & $\begin{array}{c}\text { Robust } \\
\text { s.e. }\end{array}$ & Coef. & $\begin{array}{c}\text { Marginal } \\
\text { effect }\end{array}$ & $\begin{array}{c}\text { Robust } \\
\text { s.e. }\end{array}$ \\
\hline \multicolumn{10}{|l|}{ Race and ethnic composition } \\
\hline \% black & 0.157 & 0.029 & 0.101 & 0.158 & 0.029 & 0.113 & 0.113 & 0.021 & 0.114 \\
\hline$\%$ Native American & -0.484 & -0.090 & $0.198^{\star \star}$ & -0.703 & -0.131 & $0.302^{\star \star \star}$ & -0.711 & -0.131 & $0.302^{\star \star}$ \\
\hline$\%$ Asian & -0.488 & -0.091 & 0.586 & -4.167 & -0.775 & $1.891^{* * *}$ & -3.693 & -0.680 & $1.945^{\star}$ \\
\hline$\%$ other race & 0.122 & 0.023 & 0.367 & -0.749 & -0.139 & 0.594 & -0.744 & -0.137 & 0.603 \\
\hline \% Hispanic & -0.206 & -0.038 & 0.202 & -0.835 & -0.155 & $0.484^{*}$ & -0.839 & -0.154 & $0.489^{*}$ \\
\hline \multicolumn{10}{|l|}{ Linguistic composition } \\
\hline \% language Spanish & & & & 1.201 & 0.223 & $0.452^{* * *}$ & 1.205 & 0.222 & $0.461^{* * *}$ \\
\hline$\%$ language Asian & & & & 0.567 & 0.105 & 1.857 & 0.419 & 0.077 & 1.907 \\
\hline$\%$ other language & & & & 0.010 & 0.002 & 0.250 & 0.018 & 0.003 & 0.251 \\
\hline \% linguistically isolated & & & & 0.575 & 0.107 & 0.717 & 0.454 & 0.084 & 0.727 \\
\hline \multicolumn{10}{|l|}{ Race and language interactions } \\
\hline Native American:other language & & & & -0.011 & -0.002 & 0.812 & 0.070 & 0.013 & 0.813 \\
\hline Native American:ling. isolated & & & & 1.677 & 0.312 & 1.732 & 1.821 & 0.335 & 1.734 \\
\hline Asian:language asian & & & & 73.194 & 13.613 & $27.30^{\star \star \star}$ & 72.576 & 13.36 & $27.80^{\star \star \star}$ \\
\hline Asian:other language & & & & -24.648 & -4.584 & 17.057 & -23.450 & -4.316 & 17.161 \\
\hline Asian:ling. isolated & & & & 6.983 & 1.299 & 13.803 & 7.437 & 1.369 & 13.894 \\
\hline Hispanic:language spanish & & & & -0.388 & -0.072 & 0.796 & -0.336 & -0.062 & 0.803 \\
\hline Hispanic:other language & & & & 4.378 & 0.814 & 4.984 & 4.099 & 0.754 & 5.102 \\
\hline Hispanic:ling. isolated & & & & -0.796 & -0.148 & 1.520 & -0.704 & -0.129 & 1.535 \\
\hline Other race:other language & & & & 2.835 & 0.527 & 8.779 & 3.537 & 0.651 & 9.134 \\
\hline Other race:ling. isolated & & & & 4.134 & 0.769 & $2.470^{*}$ & 3.903 & 0.718 & 2.418 \\
\hline Black:other language & & & & -3.451 & -0.642 & $1.855^{\star}$ & -3.195 & -0.588 & $1.848^{*}$ \\
\hline Black:ling. isolated & & & & 9.270 & 1.724 & $4.872^{*}$ & 9.630 & 1.772 & $4.950^{*}$ \\
\hline \multicolumn{10}{|l|}{ Income and poverty } \\
\hline median income (log) & 0.043 & 0.008 & 0.077 & 0.042 & 0.008 & 0.077 & 0.076 & 0.017 & 0.078 \\
\hline$\%$ below poverty line & -0.365 & -0.068 & 0.232 & -0.349 & -0.065 & 0.234 & -0.310 & -0.053 & 0.237 \\
\hline \multicolumn{10}{|l|}{ Size of market } \\
\hline households (log) & 0.182 & 0.034 & $0.019^{* * *}$ & 0.183 & 0.034 & $0.019^{* * *}$ & 0.179 & 0.034 & $0.019^{* * *}$ \\
\hline number of firms (log) & 0.394 & 0.073 & $0.017^{* \star *}$ & 0.387 & 0.072 & $0.017^{* \star *}$ & 0.390 & 0.074 & $0.019^{* * *}$ \\
\hline
\end{tabular}




\begin{tabular}{|c|c|c|c|c|c|c|c|c|c|}
\hline$\%$ inside urbanized area & -0.382 & -0.071 & $0.106^{\star * *}$ & -0.388 & -0.072 & $0.106^{* * *}$ & -0.398 & -0.068 & $0.109^{* * *}$ \\
\hline \% rural (non-farm), BOC telco & -0.555 & -0.103 & $0.095^{\star * *}$ & -0.558 & -0.104 & $0.095^{* * *}$ & -0.559 & -0.104 & $0.096^{* * *}$ \\
\hline$\%$ rural (non-farm), non-BOC telco & -0.624 & -0.116 & $0.085^{\star \star *}$ & -0.633 & -0.118 & $0.085^{* * *}$ & -0.626 & -0.117 & $0.087^{* * *}$ \\
\hline$\%$ rural (farm), BOC telco & -0.491 & -0.092 & $0.259^{*}$ & -0.519 & -0.097 & $0.262^{* \star}$ & -0.719 & -0.139 & $0.263^{* * *}$ \\
\hline$\%$ rural (farm), non-BOC telco & -0.104 & -0.019 & 0.169 & -0.127 & -0.024 & 0.168 & -0.169 & -0.032 & 0.170 \\
\hline \multicolumn{10}{|l|}{ Age profile of population } \\
\hline$\%$ age $<13$ yrs & 0.640 & 0.119 & 0.430 & 0.780 & 0.145 & $0.433^{*}$ & 0.569 & 0.105 & 0.436 \\
\hline$\%$ age $14-18$ yrs & -0.074 & -0.014 & 0.560 & 0.021 & 0.004 & 0.559 & -0.128 & -0.024 & 0.570 \\
\hline$\%$ age $19-24$ yrs & 1.222 & 0.228 & $0.413^{\star * *}$ & 1.293 & 0.241 & 0.415 & 1.122 & 0.206 & $0.418^{\star * *}$ \\
\hline$\%$ age $25-29$ yrs & -0.456 & -0.085 & 0.444 & -0.313 & -0.058 & 0.443 & -0.387 & -0.071 & 0.455 \\
\hline$\%$ age $30-34$ yrs & 0.675 & 0.126 & 0.466 & 0.756 & 0.141 & 0.465 & 0.651 & 0.120 & 0.466 \\
\hline$\%$ age $35-39$ yrs & 1.093 & 0.204 & $0.512^{\star \star}$ & 1.189 & 0.221 & $0.506^{\star \star *}$ & 0.928 & 0.171 & $0.513^{*}$ \\
\hline$\%$ age $40-49$ yrs & 1.021 & 0.190 & $0.379^{* * *}$ & 1.127 & 0.210 & $0.379^{* * *}$ & 0.935 & 0.172 & $0.381^{\star *}$ \\
\hline$\%$ age $50-64$ yrs & 0.694 & 0.129 & $0.346^{\star \star}$ & 0.758 & 0.141 & $0.346^{\star \star *}$ & 0.662 & 0.122 & $0.347^{\star}$ \\
\hline \multicolumn{10}{|l|}{ Education profile of population } \\
\hline$\%$ high school degree & 0.448 & 0.084 & $0.123^{\star \star \star}$ & 0.469 & 0.087 & $0.128^{* * *}$ & 0.434 & 0.080 & $0.129^{\star \star \star}$ \\
\hline$\%$ college degree & 1.066 & 0.199 & $0.260^{* * *}$ & 1.119 & 0.208 & $0.263^{\star * *}$ & 1.043 & 0.192 & $0.267^{* * *}$ \\
\hline$\%$ graduate degree & 0.396 & 0.074 & 0.385 & 0.503 & 0.093 & 0.382 & 0.545 & 0.100 & 0.383 \\
\hline \multicolumn{10}{|l|}{ Commuting profile } \\
\hline$\%$ work at home & 0.119 & 0.022 & 0.192 & 0.570 & 0.106 & $0.117^{* \star *}$ & 0.102 & 0.019 & 0.193 \\
\hline$\%$ commute $15-29$ minutes & 0.570 & 0.106 & $0.116^{\star * *}$ & 0.688 & 0.128 & $0.132^{* * *}$ & 0.504 & 0.093 & $0.118^{* * *}$ \\
\hline$\%$ commute $30-44$ minutes & 0.698 & 0.130 & $0.130^{\star \star *}$ & 1.097 & 0.204 & $0.207^{* * *}$ & 0.621 & 0.114 & $0.132^{* * *}$ \\
\hline$\%$ commute $45-59$ minutes & 1.104 & 0.206 & $0.207^{* * *}$ & 0.589 & 0.110 & $0.213^{* * *}$ & 1.023 & 0.188 & $0.206^{\star * *}$ \\
\hline$\%$ commute $60+$ minutes & 0.581 & 0.108 & $0.211^{\star * *}$ & 0.586 & 0.176 & $0.205^{\star \star \star}$ & 0.587 & 0.108 & $0.212^{\star \star \star}$ \\
\hline \multicolumn{10}{|l|}{ Other demographics } \\
\hline$\%$ female & -1.290 & -0.240 & $0.312^{\star \star *}$ & -1.326 & -0.247 & $0.314^{\star * *}$ & -1.322 & -0.243 & $0.315^{\star \star \star}$ \\
\hline$\%$ kids in household & 0.088 & 0.016 & 0.229 & 0.015 & 0.003 & 0.231 & 0.079 & 0.015 & 0.236 \\
\hline$\%$ phone in household $(<.925)$ & -0.332 & -0.062 & 0.278 & -0.260 & -0.048 & 0.279 & -0.233 & -0.043 & 0.281 \\
\hline \% phone in household (>.925) & 0.405 & 0.076 & 0.574 & 0.332 & 0.062 & 0.581 & 0.314 & 0.058 & 0.583 \\
\hline \multicolumn{10}{|l|}{ Composition of business market } \\
\hline$\%$ manufacturing firms & 0.139 & 0.026 & 0.146 & -0.093 & -0.017 & 0.124 & 0.153 & 0.028 & 0.145 \\
\hline$\%$ FIRE firms & -0.128 & -0.024 & 0.335 & 0.192 & 0.036 & 0.168 & -0.120 & -0.022 & 0.333 \\
\hline$\%$ services firms & 0.166 & 0.031 & $0.070^{* *}$ & 0.138 & 0.026 & 0.087 & 0.169 & 0.031 & $0.070^{* *}$ \\
\hline$\%$ small firms (<50 employees) & -0.754 & -0.140 & $0.103^{\star \star *}$ & -0.789 & -0.147 & $0.100^{* * *}$ & -0.724 & -0.133 & $0.102^{* * *}$ \\
\hline average employment per firm & 0.050 & 0.009 & $0.017^{* * *}$ & 0.032 & 0.006 & $0.017^{*}$ & 0.040 & 0.007 & $0.017^{\star *}$ \\
\hline \multicolumn{10}{|l|}{ Cost variables (linear splines) } \\
\hline phone density $(\log ,<0.4)$ & -0.217 & -0.040 & $0.110^{\star *}$ & -0.208 & -0.039 & $0.109^{* *}$ & -0.192 & -0.035 & $0.109^{*}$ \\
\hline phone density (log, 0.4-4.25) & 0.170 & 0.032 & 0.109 & 0.150 & 0.028 & 0.108 & 0.168 & 0.031 & 0.110 \\
\hline phone density $(\log ,>4.25$ ) & 0.122 & 0.023 & 0.141 & 0.114 & 0.021 & 0.142 & 0.098 & 0.018 & 0.142 \\
\hline population density $(\log ,<1.5)$ & 0.104 & 0.019 & 0.111 & 0.095 & 0.018 & 0.110 & 0.092 & 0.017 & 0.110 \\
\hline
\end{tabular}




\begin{tabular}{|c|c|c|c|c|c|c|c|c|c|}
\hline population density (log, 1.5-4.8) & -0.027 & -0.005 & 0.112 & -0.011 & -0.002 & 0.111 & -0.039 & -0.007 & 0.113 \\
\hline population density (log, > 4.8 ) & -0.209 & -0.039 & $0.126^{*}$ & -0.199 & -0.037 & 0.127 & -0.182 & -0.034 & 0.127 \\
\hline structure age (<17.5 years) & -0.010 & -0.002 & 0.008 & -0.011 & -0.002 & 0.008 & -0.011 & -0.002 & 0.008 \\
\hline structure age (17.5-35 years) & 0.005 & 0.001 & $0.002^{\star *}$ & 0.005 & 0.001 & $0.002^{*}$ & 0.005 & 0.001 & $0.003^{*}$ \\
\hline structure age ( $>35$ years) & -0.004 & -0.001 & 0.003 & -0.004 & -0.001 & 0.002 & -0.003 & -0.001 & 0.003 \\
\hline \multicolumn{10}{|l|}{ Bell Operating Companies } \\
\hline BellSouth & 0.307 & 0.056 & $0.091^{* * *}$ & 0.298 & 0.054 & $0.092^{* * *}$ & 0.301 & 0.058 & $0.093^{* * *}$ \\
\hline Qwest (U.S. West) & 1.214 & 0.195 & $0.125^{\star \star *}$ & 1.221 & 0.195 & $0.125^{\star \star *}$ & 1.188 & 0.193 & $0.127^{\star \star *}$ \\
\hline SBC-PacBell-Ameritech & 0.290 & 0.054 & $0.081^{* * *}$ & 0.285 & 0.052 & $0.081^{* * *}$ & 0.269 & 0.056 & $0.082^{\star * *}$ \\
\hline Verizon (Bell Atlantic-NYNEX) & 2.082 & 0.297 & $0.118^{* * *}$ & 2.086 & 0.296 & $0.119^{* * *}$ & 2.074 & 0.297 & $0.119^{\star * *}$ \\
\hline \multicolumn{10}{|l|}{ Local Telecom Competition } \\
\hline CLEC Presence & & & & & & & 0.159 & 0.267 & 0.116 \\
\hline Intercept & -2.310 & & $0.844^{* *}$ & -2.380 & & $0.828^{* *}$ & -2.617 & & $0.831^{* * *}$ \\
\hline State-level fixed effects & & yes & & & yes & & & yes & \\
\hline Number of observations & & 27,623 & & & 27,623 & & & 27,392 & \\
\hline Log likelihood & & -9154.5 & & & -9135.2 & & & -18163.0 & \\
\hline Kullback-Leibler $\mathrm{R}^{2}$ & & 0.452 & & & 0.453 & & & 0.487 & \\
\hline
\end{tabular}

* significant at the $10 \%$ level; $\quad$ ** significant at the $5 \%$ level; $\quad * * *$ significant at the $1 \%$ level.

Notes: Dependent variable is 1 if there is at least one broadband customer in the ZIP code, 0 if not. In the bivariate probit estimation, the other dependent variable is 1 if there is at least one CLEC in the ZIP code, 0 if not (coefficients from this equation are not reported here). The sample includes all states except AK, HI, DC, and DE. In third estimation, Idaho is dropped from the sample as well, due to lack of variation in the CLEC presence variable. Marginal effect is the average marginal effect on the mean in the sample; for dummy variables these are discrete changes. CLEC is Competing Local Exchange Company. See also notes to Table 2. 
Table 4

Net Effects of the Race, Ethnicity, and Language Variables on the Probability of Broadband Availability in a ZIP Code Area

\begin{tabular}{|c|c|c|c|}
\hline \multirow[b]{2}{*}{ Variables in calculation } & \multicolumn{3}{|c|}{$\begin{array}{c}\text { Percentage of areas in which there is evidence of a } \\
\text { lower probability of broadband access }\end{array}$} \\
\hline & raw & $\begin{array}{c}\text { weighted by } \\
\text { minority population }\end{array}$ & $\begin{array}{l}\text { weighted and significant } \\
\text { at the } 5 \% \text { level }\end{array}$ \\
\hline $\begin{array}{l}\text { Asian, Asian language, As ian:Asian language, } \\
\text { and Asian:linguistically isolated }\end{array}$ & $94.8 \%$ & $73.8 \%$ & $54.3 \%$ \\
\hline $\begin{array}{l}\text { Black, black:other language, and } \\
\text { black:linguistically isolated }\end{array}$ & $43.6 \%$ & $2.6 \%$ & $0.00 \%$ \\
\hline $\begin{array}{l}\text { Hispanic, Spanish language, } \\
\text { Hispanic:Spanish, and } \\
\text { Hispanic:linguistically isolated }\end{array}$ & $25.7 \%$ & $58.4 \%$ & $0.06 \%$ \\
\hline $\begin{array}{l}\text { Native American, Native American:other } \\
\text { language, and Native } \\
\text { American:linguistically isolated }\end{array}$ & $99.9 \%$ & $99.8 \%$ & $89.2 \%$ \\
\hline $\begin{array}{l}\text { Other race, other race:other language, } \\
\text { and other race:linguistically isolated }\end{array}$ & $97.1 \%$ & $63.2 \%$ & $0.00 \%$ \\
\hline $\begin{array}{l}\text { All race, ethnicity, language, and interaction } \\
\text { variables }\end{array}$ & $48.9 \%$ & $51.1 \%$ & $13.5 \%$ \\
\hline
\end{tabular}

Notes: "evidence of a lower probability of broadband access" in an area means that the combined marginal effect of the variables in

the first column on access probability is negative. Raw figures are calculated as $\Sigma_{i} 1\left\{x_{i}^{\prime} b<0\right\} / N$, where $1\{a\}$ is the indicator function taking a value of 1 if a is true and zero otherwise, $i$ indexes observations, and the variables included in vector $x_{i}$ are given in the row headings. Variables of the form $a: b$ are interactions. Sample values are used for $x_{i}$; coefficient estimates $b$ are taken from the probit with state fixed effects in Table 3. In the second column, the summand is weighted by the relevant minority population (the first variable listed in the row headings) in the ZIP code. In the third column, an area is counted (and weighted, as in previous column) if it has a negative effect large enough to reject the null hypothesis that $x_{i}^{\prime} b>0$ at the $5 \%$ level. 
Figure 1: A Stylized Depiction of DSL and Cable Modem Internet Access

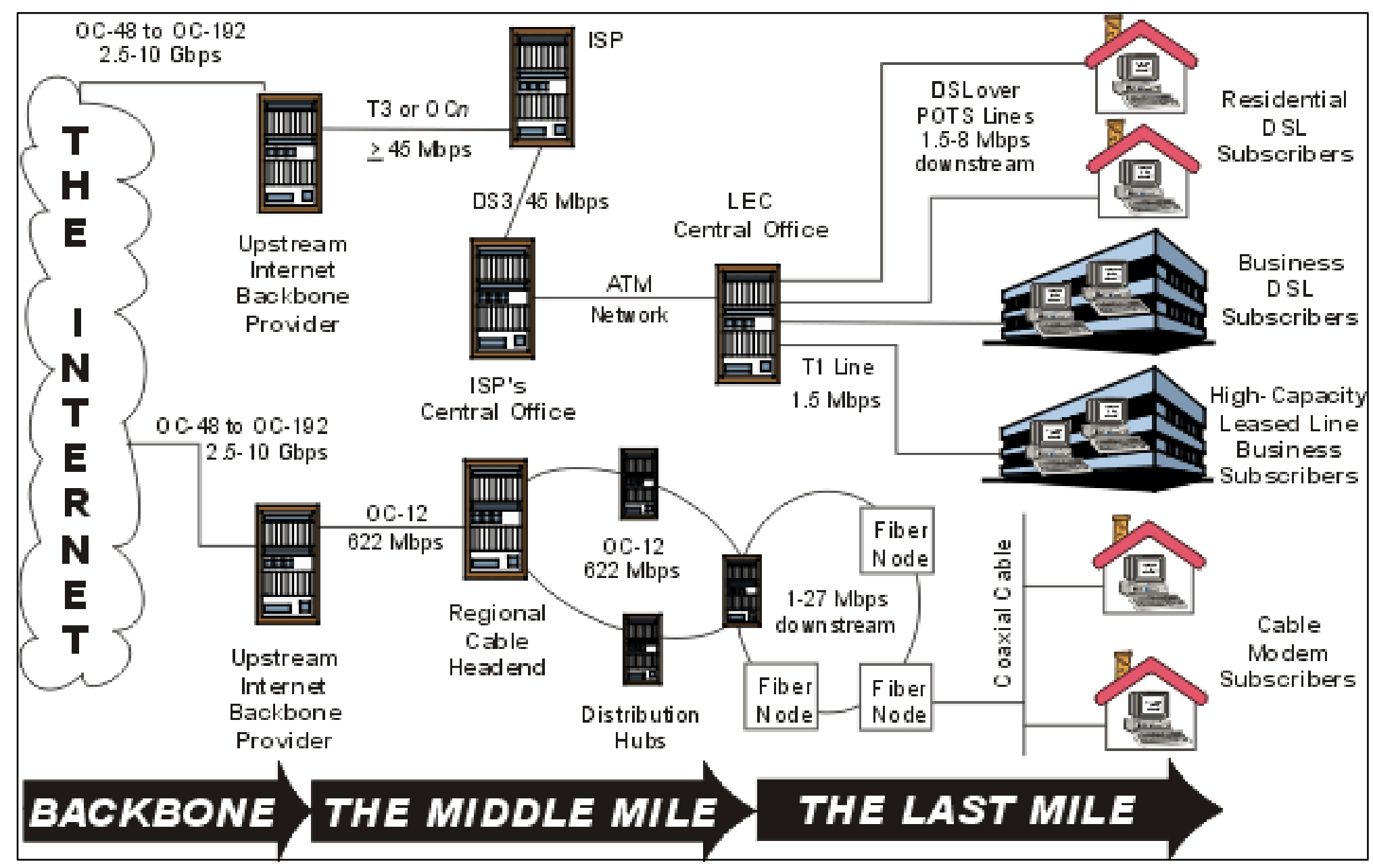


Figure 2:

Choice of Broadband Technology by Residences and Small Businesses

\section{Residential and Small Business High-Speed Lines}

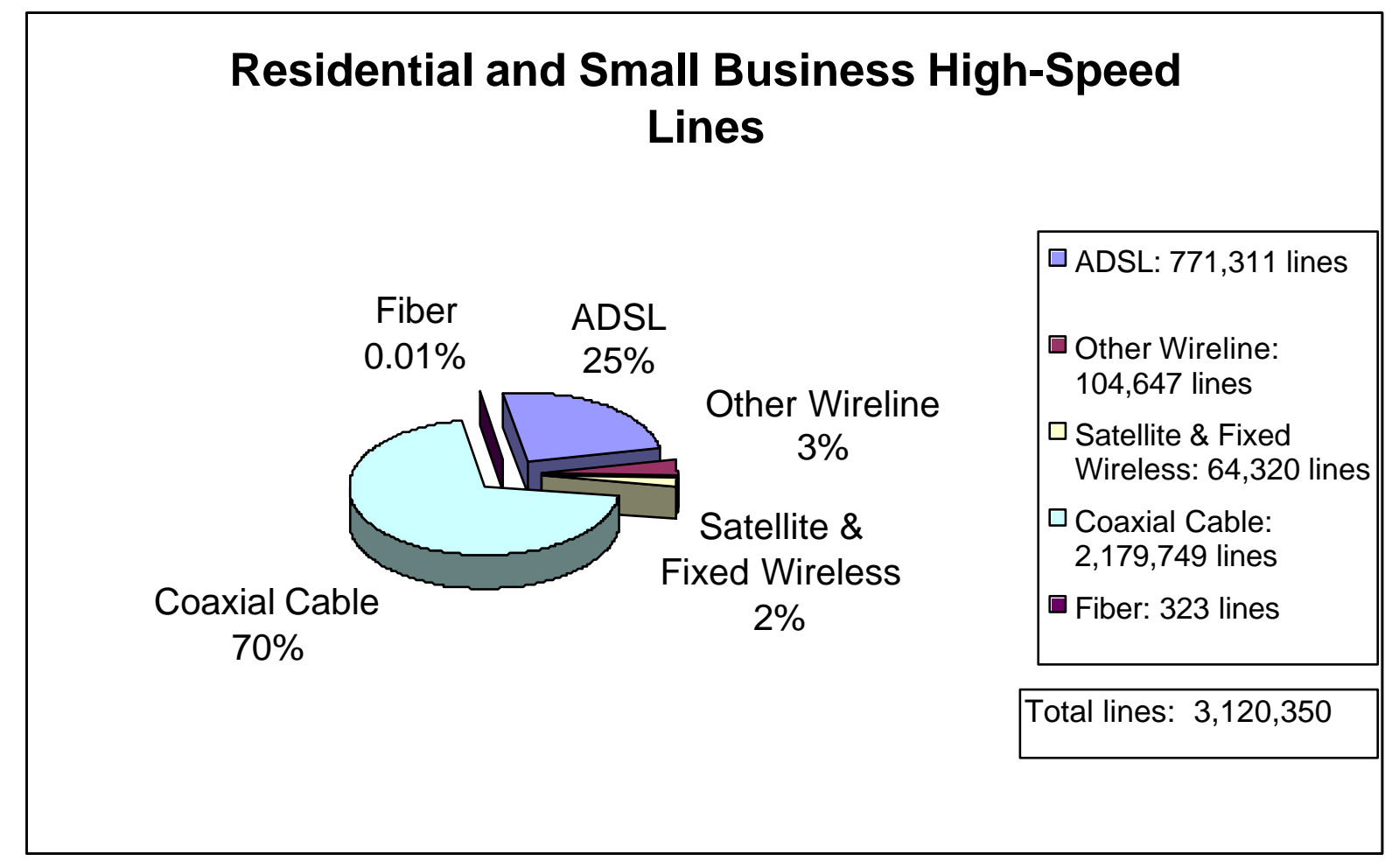

Source: FCC (2000b) 
Figure 3: Choice of Broadband Technology by Larger Bus inesses

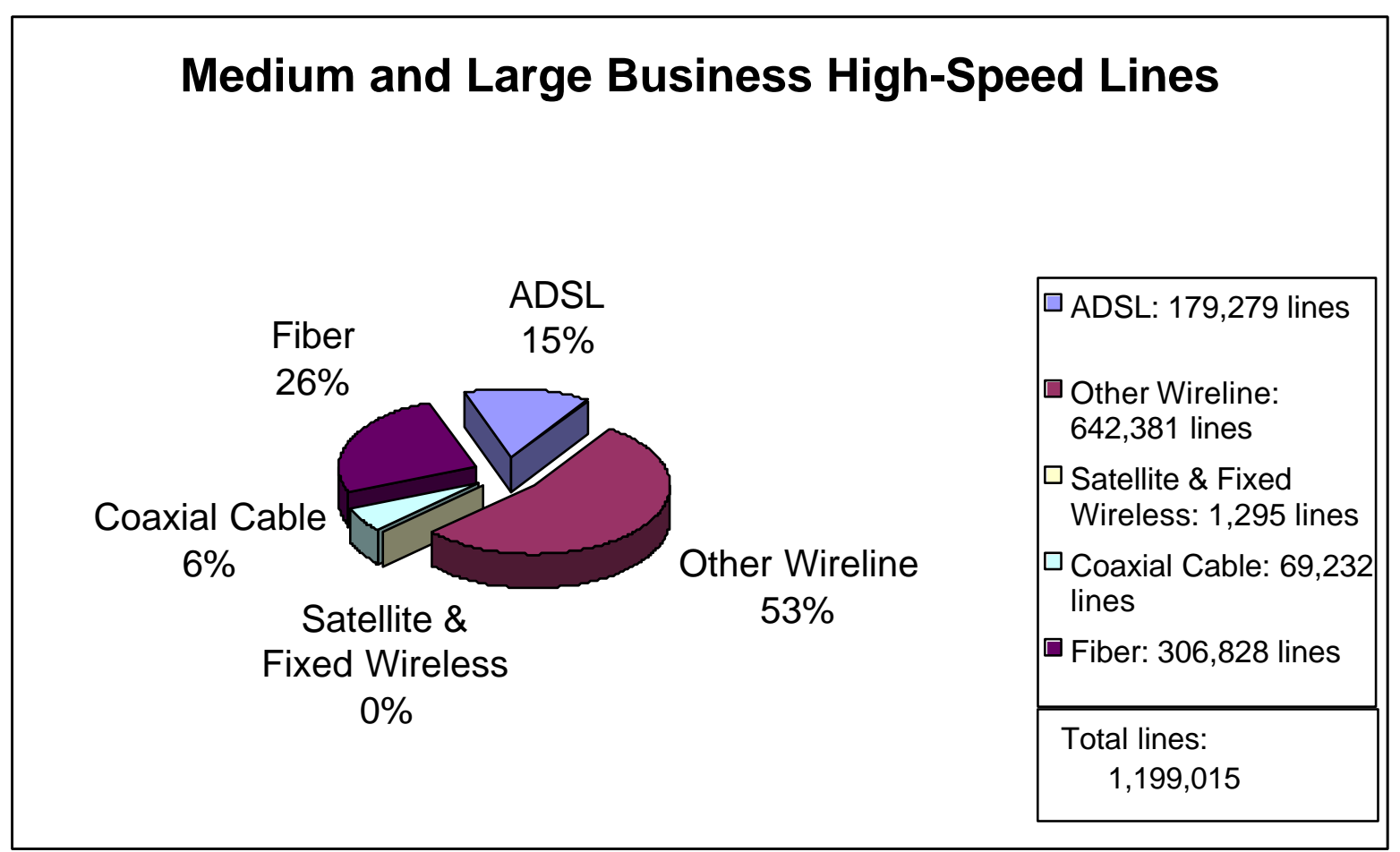

Source: FCC (2000b) 
Figure 4: Broadband Availability by Number of Providers of Any Type as of June 2000.

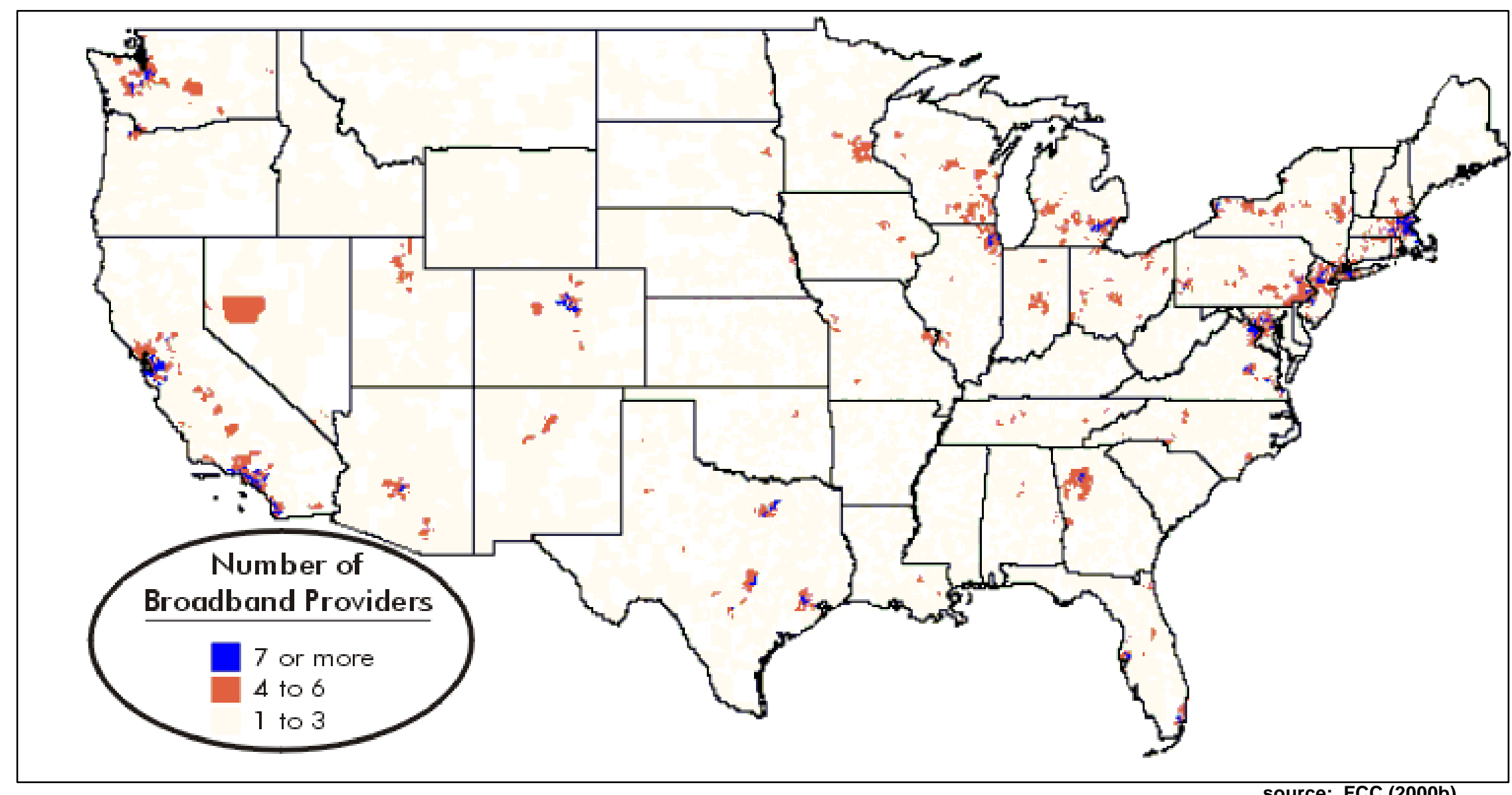


Figure 5: Partial nonparametric fits of the variables \% Asian population and \% Native American population

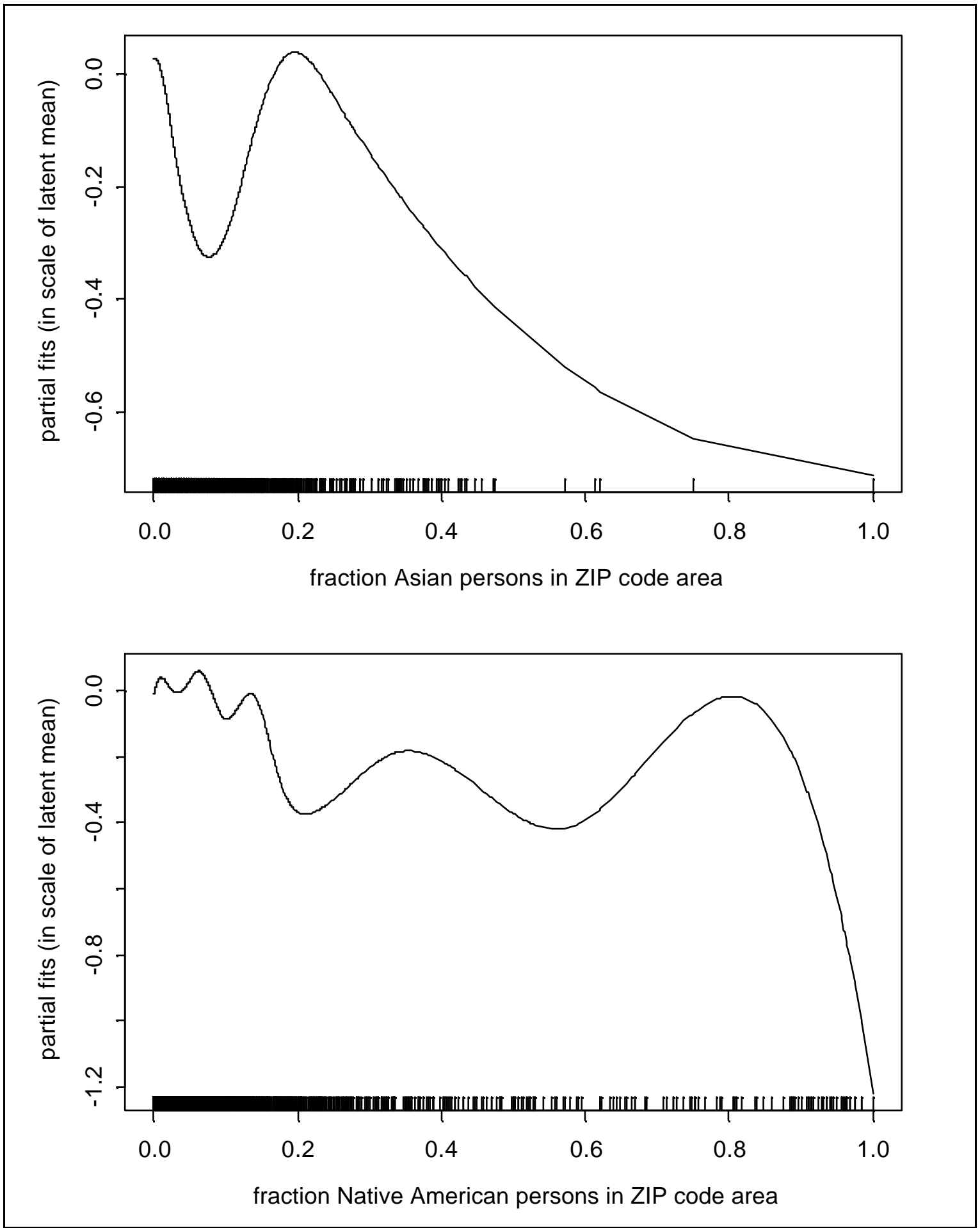

Figure contains the partial fits from nonparametric cubic B-splines. Positive slopes imply positive marginal effects of the variable on broadband availability. Ticks at bottom of plots mark the sample data. Abscissae are calibrated so the $y$ value is zero at the mean $x$ in the sample. 